\title{
Comparison of Riveted, Bonded \& Hybrid Joints using FEA
}

\author{
Bhupendra S Ahire ${ }^{1}$, Prof. Sharad D. Kachave ${ }^{2}$ \\ PG Student, Department of Mechanical Engineering, SSVPS COE Dhule, Maharashtra, India ${ }^{1}$ \\ Associate Professor, Department of Mechanical Engineering, SSVPS COE Dhule, Maharashtra, India ${ }^{2}$
}

\begin{abstract}
The need of design lightweight structures and the increase use of lightweight materials in industrial fields, have lead to wide use of adhesive bonding. Most widely used material as Composite materials for structural element in aircraft structure like huge assembly of frames, skins, spars etc. and also used in automobile body parts like hood, trunk, doors, and roof. These joints are manufacture by Riveted joints. Failure of components occurs due to lots of reasons such as stress concentration excessive deflection or combination of these. By the application of various joining techniques try to identify stress concentration at particular location and strength of joint so that the suitable configuration can be chosen for various applications. Modeling, manufacturing (bonded, riveted, hybrid joint) and static analysis of 3D models will carry out using FEA software. The results will be interpreted in terms of Von Mises Stress. Various joints like Bonded, Riveted, and Hybrid joint were prepared and tensile test will carry out to evaluate results to identify their load bearing capacity.
\end{abstract}

Keywords: static analysis, FEA software, Von Misses stress.

\section{INTRODUCTION}

Nowadays, for designing aircraft structure composite material is used which consist of high strength to weight ratio, which impacts the desire performance. However, the joining of various parts made of composite materials is a complex matter. Drilling holes in composite material reduces strength of joint and lead to delimitation. We are using additional mechanical fasteners it increases the weight of structure. This is partially why bonding of composite materials has become very popular. Bonded joints offer higher static and fatigue strength as well as higher strength to mass ratios than other joining methods. To improve performance of bonded joint for aeronautical certification purposes, research on the combination of bonded joints or rivets, called hybrid joints, which has major interest. Properties of composite materials are superior under this conditions composite materials are used for the existing structures. In such applications and also for joining various composite parts together, they are fastened together either using adhesives or mechanical fasteners. Nowadays, a hybrid joint is called novel method also being employed, where a combination of both mechanical fastener and adhesive is used. Hybrid joints have a combination of mechanical fasteners and adhesive bond. There is advantages of using a combined bondedriveted design apply mainly in are pair situation.

\section{LITERATURE REVIEW}

Nabil Chowdhury, Wing Kong Chiu, John Wang, Paul Chang The static strength and fatigue resistance of mechanically fastened, bonded and hybrid double lap joints using relatively thin carbon fibre adhere ends have been experimentally investigated. The aim was to compare
The static strength and fatigue resistance of a hybrid joint configuration consisting of bonding and riveting, a purely riveted joint and a purely bonded joint.

Mark outlet and aurelian vadean [1] worked on the performance of a hybrid (bolted/bonded) joint and this performance depends on many parameters. Its design becomes complex when the design aims to create a combination between these two joining methods which are commonly used for composite plates. In this paper, axiomatic design is applied to identify the parameters that affect the load transfer between the maximum stresses in the adhesive as well as different component of joints. Couple the design of joint it is necessary to decomposition of joint into two parts first functional requirement and second design parameters. A uncouple design were produced through the reforming and reordering of both functional requirements and design parameters. The new matrix is then used to produce a new design through integration of the design parameters. Mark compare the results of this new design and pervious geometry which shows the reduction in the maximum stress concentration inside the joint in new design. At higher load transfer capability this improvement should also result, while maintain at same dimension.

Raviraja.S and L.Nafeez Ahmed [2] proposed a paper on "FEA and Experimental Evaluation of Bonded, Riveted and Hybrid Joints in Glass Fibre Epoxy Composite Laminates" in this paper they studied Manufacturing of the composite joints like bonded, riveted and hybrid, modeling and static 3D analysis were conducted using FEA software. The results of the Hybrid joint were 
Vol. 4, Issue 1, January 2017

evaluated in terms of shear stress, total deformation and Von Misses stress. Composite Glass fibre epoxy material was used to prepare various joints and experimental test were carried out on these components. These experimental results were compared with the software results to calculate load bearing capacity.

S. B. Belkar, M. S. Mhaske, and Swapnil S. Kulkarni [3] studied "Evaluating the Shear Strength of a Hybrid JointAdhesive a Rivet for Potential Applications in Aerospace Industry" that Hybrid joints have a combination of mechanical fastener and adhesive bonding. Combine design of bonded riveted joint has great advantage, results were interpreted to evaluate best joint.

Ana C. F. Silva, Daniel F. O. Braga, M. A. V. de Figueiredo [4] worked on "Ultimate tensile strength optimization of different FSW aluminium alloy joints" they proposed Friction stir welding (FSW) is a highly reliable joining process and optimization is carried out. While optimizing FWS parameter for different joint configurations there is still lack of optimized FSW parameters. The present paper gives a set of optimization studies for different friction stir welding joint geometries of AA6082-T6 aluminium alloy: butt, lap and T joints. The parameters were optimized using Taguchi arrays (OA) for designing experiments, analyses of the average effects (main effect plot) and variance (ANOVA). In this paper they studied the parameters affecting to stress values it should below UTS. The parameter combinations to achieve the best mechanical properties for each joint configuration were derived.

Kale Suresh, K. L. N. Murty \& T. Jayananda Kumar [5] This paper deals with the analysis of adhesively bonded single lap riveted joints. The present work involves the characterization of these joints and appropriate configuration for maximum utilization. In this paper they proposed by varying bond line thickness and configuration of bond line thickness at various locations of joint bondedriveted joint has more strength than the riveted joint. It is also possible to evaluate results for different materials. The finite element technique was applied throughout the analysis of present work. The riveted bonded joint seems too balanced condition, the stress and distributed uniformly. This improves the performance, efficiency and life time of the riveted joints; this is also applicable to dissimilar metal joints and dissimilar metal thickness for balancing, uniform distribution of stress and without any effect of corrosion on dissimilar metals. Modeling and analysis of adhesively bonded single riveted lap joint can be done by using ansys with a version of 13.0.

K. Mohamed Bak, K. PrasannaVenkatsen and K. Kalai Chelvan [6] In the present study, FEA for the prediction of stress distribution in bonded, riveted and hybrid joints has been carried out. Von mises stress was used to compare the results. It was investigated that a well-designed hybrid joint gives better performance when compared to bonded or riveted joint.
T. Sadowski, T. Balawender, R. Sliwa, P. Golewski, M. Knec [7] The results investigated within the paper lead to the following major conclusions: the strengthening of simple joints (clinching, riveting and spot welding) by application of adhesive significantly improve, load carrying capacity of joint, static strength. In simple adhesive Bond strength is high. While calculating energy consumed by the specimen to the final failure shows several times higher in case of the hybrid joints, the greater force values were obtained for hybrid specimens prepared by clinching before curing, the final failure of the hybrid joined structural system significantly depends on the type of the applied adhesive during specimen manufacturing and the surface adhesive area. At higher fracture load properties of the adhesive layer can affect the level of loading capacity and increase the energy absorption capacity up to the final failure, the stiffening effects of the hybrid joint lead to higher reliability and durability of the structural joints.

\section{A. Outcome of Literature Review}

The main problem to be analysed in this paper is estimation of an influence of rivet geometrical layout on the hybrid adhesive bonded/riveted joints response to mechanical loading. The further improvement of the structural elements joining technology is to combine two simple joining techniques.

\section{III.BASIC THEORY OF BONDED RIVETED HYBRID JOINT}

\section{A.COMPOSITE JOINT}

Ideally, composite material is always preferred to make monolithic structures, that is, structures without joints. This ideal can never be realized for many reasons like size limitations imposed by manufacturing process or materials, need for disassembly of structure for transportation and access for inspection and repair etc. Basically, there are two types of load-carrying joints available: Adhesively bonded joint and mechanically fastened joints. Nowadays, a novel method called hybrid joint is also used in certain applications.

Reaching a decision about the type of joints to be used requires careful considerations of several parameters together with the knowledge of the service that the joint is expected to provide. Thus a requirement for disassembly and lack of adequate preparation facilities would certainly preclude bonding; a requirement to join thin sheets might rule out the use of mechanical fasteners whereas heavily loaded joints are designed using mechanical attachments. A short description of the type of joint used in the present work namely, bonded joint is given below.

\section{B.BONDED JOINT}

Bonded joints have been made by gluing together precured laminates by forming joints during the manufacturing process or with the suitable adhesives, in which case the joint and the laminate are cured at the same time (co-cured). Here, distribution of shear stress in 


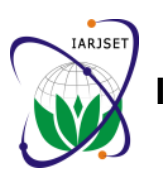

IARJSET

Vol. 4, Issue 1, January 2017

adhesive will takes place due to application of load to substrate.

In general, there are various advantages of adhesively bonded joint over the mechanical fastened joints. These advantages include high strength to weight ratio, low stress concentration, large bond area for load transfer, smooth external surfaces at the joint, less sensitivity to cyclic loading, electrical and thermal insulation, conductivity, time and cost saving, corrosion and fatigue resistance, crack retardation, damping characteristic and so on Some of the disadvantages of bonded joints are

1. Disassembly is impossible without component damage. 2. They can be severely weakened by environmental effects.

3. They require surface preparation.

4. Joint integrity is difficult to confirm by inspection. Thus ensuring a quality of bonding has been a challenging task.

\section{C.STRENGTH AND LOAD TRANSFER IN HYBRID JOINTS}

When designing a mixed technology of joining, one of the goals is to take advantage of the strengths of each joining method or simply to improve the performance of the first one by adding additional joining methods. One of the main emphasis of research is distribution of the loading within the joint is one of the main.

Thus, one of the most important studies was performed by Hart-Smith who conducted an analytical study of the performance of a bonded/bolted composite to titanium stepped lap-joint.

Using a high rigidity adhesive, the author predicted that the adhesive would transfer up to $98 \%$ of the external load. When using a low rigidity adhesive, Kelly showed that, in a single bolt single-lap hybrid joint, the bolt could transfer up to $32 \%$ of the external load. With similar results, Kweon concluded that, for low strength adhesive, the addition of bolts greatly increases the strength of the joint while, for high strength adhesive, it is almost without results. In the case of high rigidity adhesive, the bolts start transferring load only after the initial failure of the adhesive, thus helping to slow down the crack propagation [Hart-Smith].

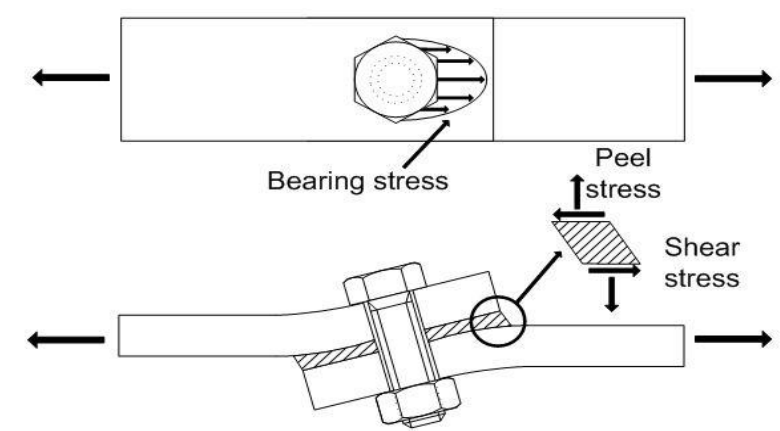

Fig. 1Principal stress distribution in a single-lap hybrid joint. [1].
This mechanism confers higher rigidity of hybrid joints at high external loads as well as improved fatigue life compared to bonded joints. Moreover, the addition of bolts in a bonded joint can also ensure structural integrity even after complete adhesive failure.

Many authors worked on promising analytical models to predict the stress distribution and the load transfer distribution in the joint. However, the use of linear material properties in the definition of these models reduces their usefulness without systematic comparison with test results or finite element analysis results.

\section{IV.METHODS AND METERIAL SELECTION}

Modeling and static analysis of 3D models of the joints (bonded, riveted and hybrid) are made by using Ansys FEA software. The results were interpreted in terms of Von Mises stress.

\section{D.SOFTWARE PROCEDURE}

The analysis is made in ANSYS APDL. The combination of MS-MS, AL-AL, CF-CF plate is made, accordingly the material Properties are applied by material Attributes. The boundary conditions used are one end of Geometry is fixed and the force is applied at another end, for the riveted joints the rivets are also fixed or glued to both plates by Boolean operations. The results are obtained in the form of Von Mises Plot.

\section{E.EXPERIMENTAL PROCEDURE}

All the Experimentation is done on Universal Testing Machine using data acquisition system. The upper end is fixed and load is applied at another end till the joints are failed. The stresses and Deformations are obtained from UTM.

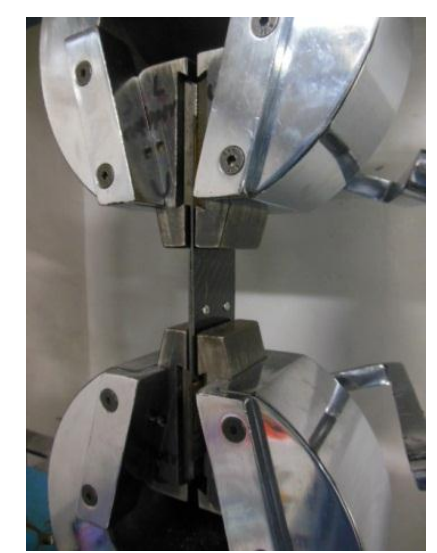

Fig2: Experimental Procedure of CF-CF Tensile Test.

TABLE 1 MATERIAL PROPERTY $[2,10]$

\begin{tabular}{|c|l|}
\hline \multicolumn{2}{|c|}{ Plate Dimension } \\
\hline \multirow{4}{*}{ Materials For Plates } & 1) Aluminium \\
& 2) Mild Steel \\
& $\begin{array}{l}\text { 3) Composite (Carbon } \\
\text { Epoxy) }\end{array}$ \\
\hline
\end{tabular}


International Advanced Research Journal in Science, Engineering and Technology

ISO 3297:2007 Certified

Vol. 4, Issue 1, January 2017

\begin{tabular}{|c|c|c|c|}
\hline Material & $\begin{array}{c}\text { Alumini } \\
\text { um }\end{array}$ & Steel & $\begin{array}{c}\text { Carbon } \\
\text { Epoxy }\end{array}$ \\
\hline $\begin{array}{c}\text { Young's } \\
\text { modulus } \\
\text { (N/mm })\end{array}$ & $\begin{array}{c}0.69 \times \\
10^{11}\end{array}$ & $2.1 \times 10^{11}$ & $3 \times 10^{6}$ \\
\hline $\begin{array}{c}\text { Poisson's } \\
\text { Ratio }\end{array}$ & 0.33 & 0.3 & 0.25 \\
\hline $\begin{array}{c}\text { Density } \\
\left(\mathbf{k g} / \mathbf{m}^{\mathbf{3}}\right)\end{array}$ & 2700 & 7850 & 1799 \\
\hline
\end{tabular}

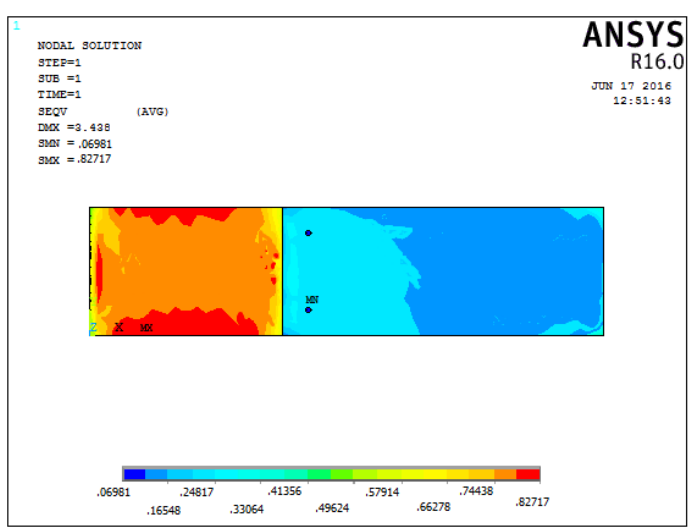

(b)Hybrid Plate Al-Al

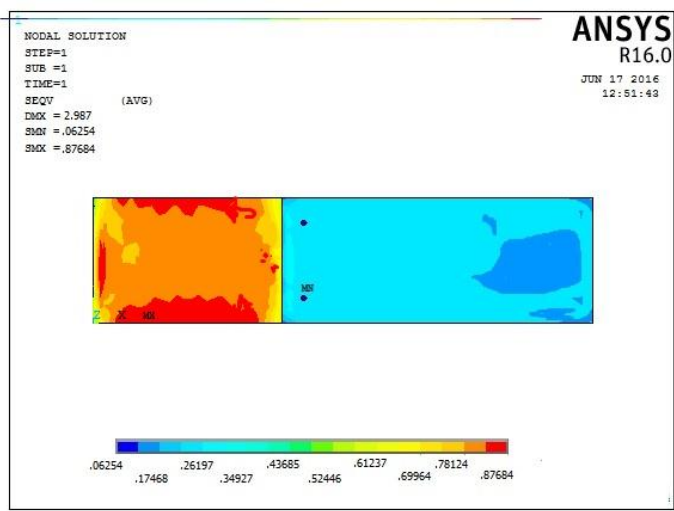

(c) Hybrid Plate Carbon Epoxy-Carbon Epoxy

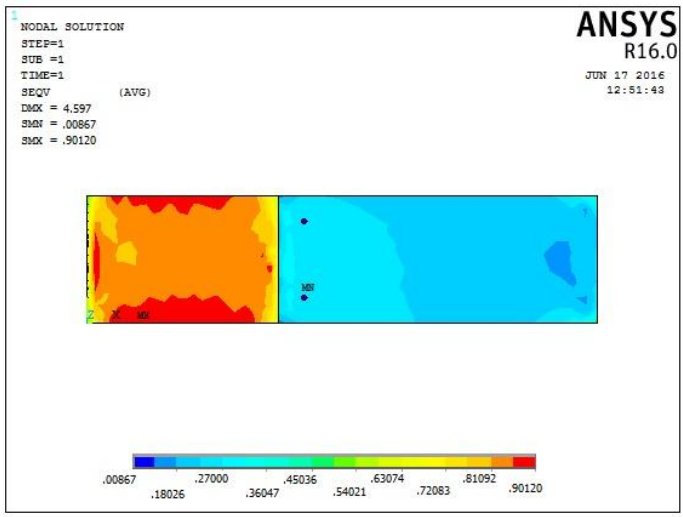

(d) Hybrid Plate MS-MS ends

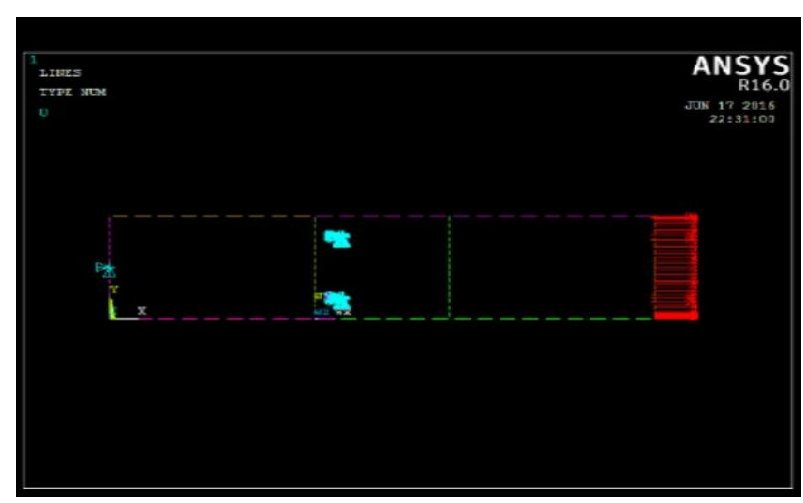

(a) Boundary condition

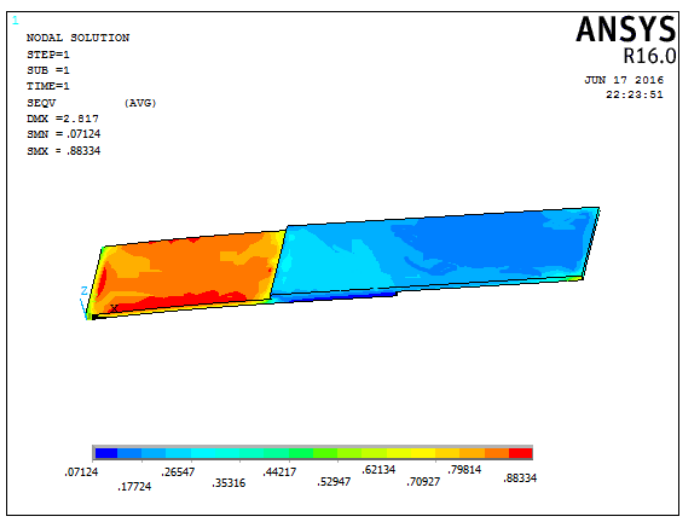

(e) Bonded PlateCarbon Epoxy-Carbon Epoxy 
Vol. 4, Issue 1, January 2017

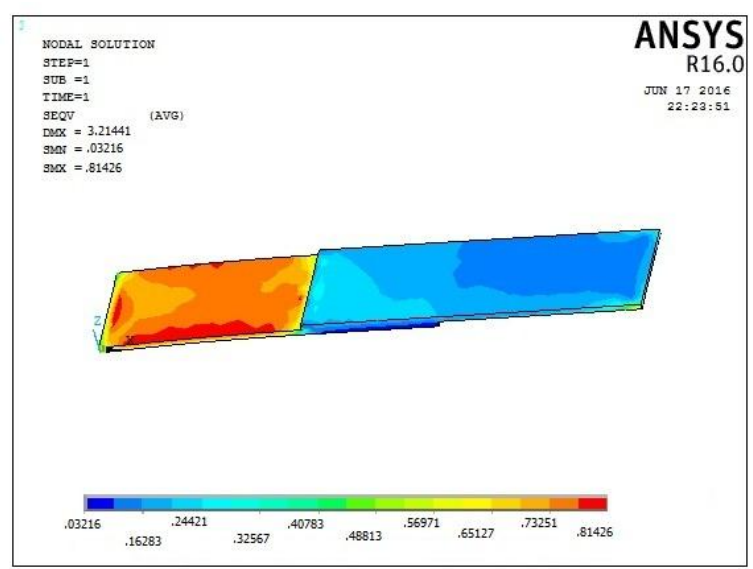

(f) Bonded Plate AL-AL

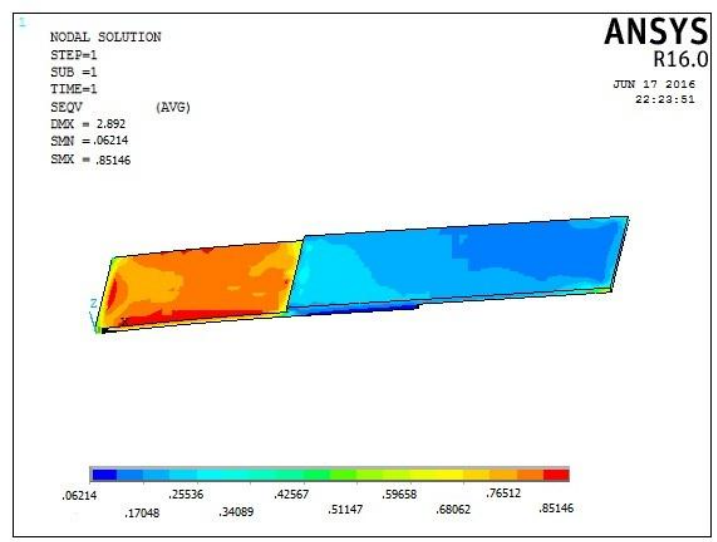

(g) Bonded Plate MS-MS

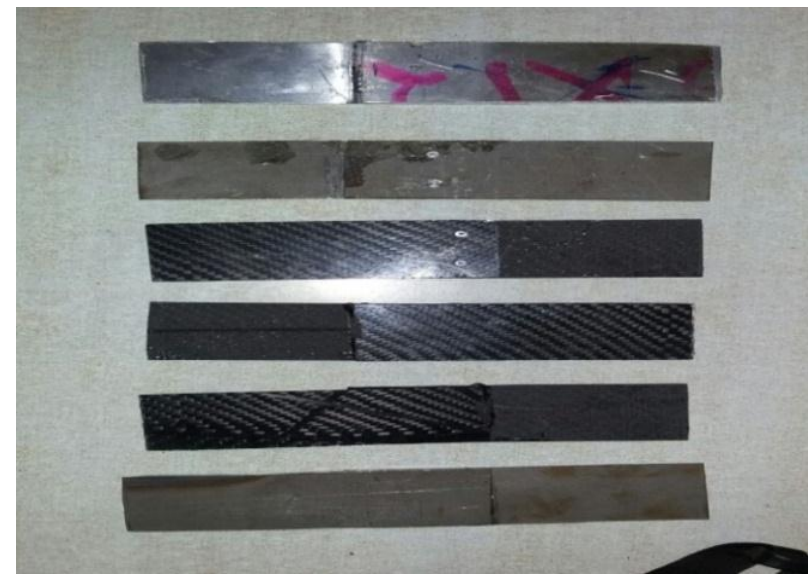

(h) Test components

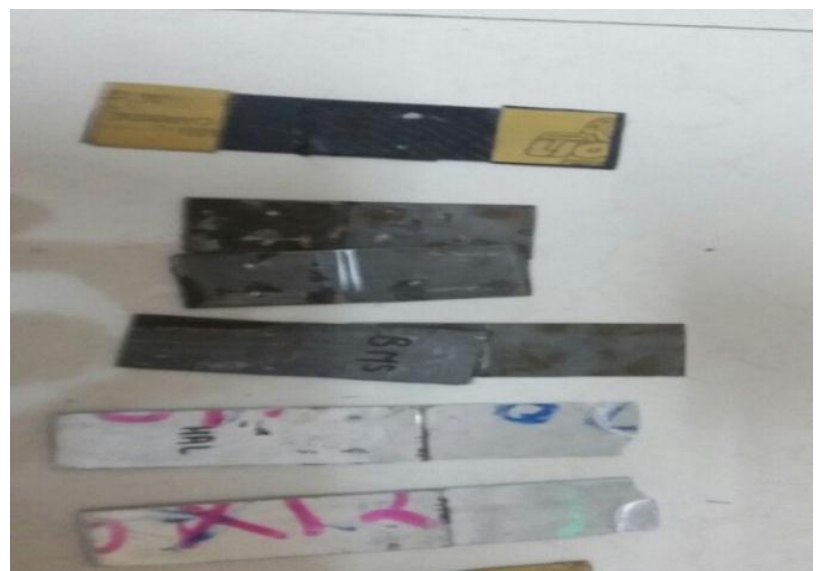

(i) Tested components under UTM

\section{RESULTS}

Tensile test results

\begin{tabular}{|c|c|c|c|c|}
\hline Sr. No & \multicolumn{2}{|c|}{ Combination } & $\begin{array}{l}\text { Max. Von Mises Stress } \\
\text { (SOFTWARE) N/mm }\end{array}$ & $\begin{array}{l}\text { Max. Von Mises Stress } \\
\text { (Experimental) N/mm }\end{array}$ \\
\hline 1 & \multirow[t]{3}{*}{ Riveted } & MS-MS & 0.083 & 0.106 \\
\hline 2 & & AL-AL & 0.037 & 0.045 \\
\hline 3 & & $\begin{array}{l}\text { Composite- } \\
\text { Composite }\end{array}$ & 0.667 & 0.877 \\
\hline 4 & \multirow[t]{3}{*}{ Bonded } & MS-MS & 0.851 & 0.822 \\
\hline 5 & & AL-AL & 0.814 & 0.784 \\
\hline 6 & & $\begin{array}{l}\text { Composite- } \\
\text { Composite }\end{array}$ & 0.883 & 0.872 \\
\hline 7 & \multirow[t]{3}{*}{ Hybrid } & MS-MS & 0.901 & 0.873 \\
\hline 8 & & AL-AL & 0.827 & 0.786 \\
\hline 9 & & $\begin{array}{l}\text { Composite- } \\
\text { Composite }\end{array}$ & 0.876 & 0.868 \\
\hline
\end{tabular}

\section{RESULT AND DISCUSSION}

From above table it is observed in results that the carbon fibre plate joints are stronger, in all three cases riveted, bonded, and hybrid cases. Riveted joints fail at very less loads, whereas hybrid joints are healthier comparatively, also it depends on the hardener used and time taken for hardening. .

\section{CONCLUSION}

The results from the analysis of the models were interpreted in terms of Von Mises stress. There are three "Principal Stresses" that can be calculated at any point, 
Vol. 4, Issue 1, January 2017

acting in the $\mathrm{x}, \mathrm{y}$, and $\mathrm{z}$ directions. "Von Mises Stress" is then compared to the yield stress of the material. The yield stress is a known property of the material, and is usually considered to be the failure stress. A short interpretation of the results of the analysis is given below. In Riveted Joints the stresses developed are comparatively high and acting at the rivet section, it can be concluded that the geometry and number of rivets influences the stresses and the life of the joints. In bonded joints the stresses are developed throughout the cross section of joint and the values of stresses are less comparatively bonded joints cannot be applicable for high loading; the life of bonded joints is less. Hybrid joints provide better strength. These joints are more reliable than the riveted and bonded joints. Future scope for this project will be increase thickness of adhesive layer in case of Hybrid joint for better performance and efficiency.

\section{ACKNOWLEDGEMENT}

Author have greatly acknowledged to the Department of Mechanical engineering of SSVPS COE, Dhule for their kind support.

\section{REFERENCES}

[1] Mark Ouellet and Aurelian Vadean, "Design improvement of Hybrid composite joint by axiomatic design", june2013.

[2] Raviraja.S and L.Nafeez Ahmed, "FEA and Experimental Evaluation of Bonded, Riveted and Hybrid Joints in Glass Fibre Epoxy Composite Laminates", Volume 4, March2015.

[3] S. B. Belkar, M. S. Mhaske, and Swapnil S. Kulkarni, "Evaluating the Shear Strength of a Hybrid Joint-Adhesive a Rivet for Potential Applications in Aerospace Industry", Oct.-Dec, 2014/36-38.

[4] Ana C. F. Silva, Daniel F. O. Braga, M. A. V. de Figueiredo "Ultimate tensile strength optimization of different FSW aluminium alloy joints", 18 February 2015Springer-Verlag London 2015.

[5] Xiaoyun Liao \& G. Gary Wang, "Simultaneous optimization of fixture and joint positions for non-rigid sheet metal assembly", 4 January 2007Springer-Verlag London Limited.

[6] Kale Suresh, K. L. N. Murty\& T. Jayananda Kumar, "Evaluating the Shear Strength of a Hybrid Joint-Adhesive a Rivet for Potential Applications in Aerospace Industry"

[7] K.Mohamed Bak, K. PrasannaVenkatsen and K. KalaiChelvan, Oct.-Dec, 2014/36-38.

[8] S.Venkateswarlu, K. Rajasekhar, "Modelling and Analysis of Hybrid Composite Joint Using Fem in Ansys",June 2013.

[9] T.Sadowski, T. Balawender, R. Sliwa, P. Golewski, M. Knec,'Experimental and FE analysis of Bonded Single-lap Joints Strengthened by Self-tapping Screws".

[10] Nabil M. Chowdhury, Wing Kong Chiu, John Wang, Paul Chang work on "Experimental and finite element studies of bolted, bonded and hybrid step lap joints of thick carbon fibre/epoxy panels used in aircraft structures."

[11] V. Fiore, L. Calabrese, E. Proverbio, R. Passari, A. Valenza a work on "Salt spray fog ageing of hybrid composite/metal rivet joints for automotive applications"

[12] T. Löbel D. Holzhüter, M. Sinapius C. Hühne work on A hybrid bondline concept for bonded composite joints

[13] P. S. G. Design data book. 